\title{
Isocyanate asthma: respiratory symptoms due to 1,5-naphthylene di-isocyanate
}

\author{
M G HARRIES, P SHERWOOD BURGE, M SAMSON, A J NEWMAN TAYLOR, \\ AND J PEPYS
}

From the Brompton Hospital, London, UK

\begin{abstract}
Occupationally related asthma developing in three patients due specifically to exposure to 1,5-naphthylene di-isocyanate (NDI), a hot curing agent used in manufacturing rubber, has been confirmed for the first time using bronchial provocation testing. This substance has been thought to be safer than toluene di-isocyanate (TDI) and diphenylmethane di-isocyanate (MDI) because of its relatively high melting point $\left(120^{\circ} \mathrm{C}\right)$.

Each patient worked in the same factory and the circumstances of exposure were similar. Provocation testing was also performed with TDI in concentrations up to 0.018 parts per million (ppm) and MDI in concentrations up to $0.02 \mathrm{ppm}$, to which the patients had been exposed in the past, but no reactions were elicited. None of the patients had increased bronchial reactivity judged by histamine lability and exercise testing.

Each patient was advised to give up his job, but two of the three could not find alternative employment and remained exposed. Three-year follow-up shows that airways narrowing has persisted in those who have remained exposed.
\end{abstract}

Respiratory symptoms resulting from exposure to di-isocyanates have been recognised since the first report by Fuchs and Valade (1951) of reactions to toluene di-isocyanate (TDI). Symptoms of asthma may follow inhalation of the vapour of these compounds. The more volatile isocyanates, TDI and hexamethylene di-isocyanate (HDI), cause asthma at room temperature while solid isocyanates, diphenylmethane di-isocyanate (MDI) and 1, 5naphthylene di-isocyanate (NDI) seldom cause problems unless they are heated (Longley, 1964; Munn, 1965; Tanser, 1973).

NDI is a solid with a melting point of $120^{\circ} \mathrm{C}$. Goldblatt and Goldblatt (1956) and Munn (1965) both describe instances in which the development of asthma was thought to result from exposure to the vapour of NDI.

We describe three patients in whom asthma developed for the first time while they were working in a factory where various isocyanates were used and whose asthma was thought to be caused by the vapour of NDI, a hot curing agent used in manufacturing synthetic rubber. Using occupational-type bronchial provocation testing these symptoms were shown to result specifically from exposure to NDI vapour.

\section{Case reports}

\section{PATIENT 1}

This 46-year-old man had been engaged in 1955 as a chemist in a factory making plastic moulds using a two-part mix with either TDI, MDI, or NDI as the curing agents. He noticed a cough at work then. In 1962 he developed breathlessness and tightness in the chest especially at night and ultimately during the day. He noticed that his symptoms improved at weekends and on holiday when away from work. In 1972 the factory moved its location but undertook no change in methods of manufacture or in use of materials. His symptoms continued. He had smoked 40 cigarettes a day until 1974 and was atopic but with no past history of eczema or rhinitis. He was admitted to hospital for bronchial provocation testing in November 1975.

\section{PATIENT 2}

This 41-year-old man worked as a foreman in the same factory as the first patient at its new location and was known to have been exposed to TDI for one year in 1963. He was referred to hospital in December 1974 with a nine-month history of nasal 
discharge and watering of the eyes and with a single attack of asthma after an upper respiratory infection. He was atopic and had airways obstruction with an FEV 1 of 2.51 and an FVC of 3.41 , which at that time was attributed to his smoking (40 cigarettes a day). He returned to work with recurrence of wheeze and shortness of breath, always worse first thing in the morning. His FEV $_{1}$ and FVC measured at work six hours after starting his shift showed a fall from 2.41 and 3.21 respectively to $1 \cdot 11$ and $2 \cdot 251$. After a period off work he improved but during that time was given oral corticosteroids. In May 1975 he inhaled the fume of a mixture of NDI powder and prepolymer resin that was being heated in a fume cupboard at $135^{\circ} \mathrm{C}$. Within 30 minutes he was short of breath and suffered wheeze for the next two days. He was admitted to hospital for bronchial provocation testing in June 1975.

\section{PATIENT 3}

This 37-year-old man worked for six years as a moulder of plastic and then as a polyurethane caster at the same factory as the first patient both at its old location and the new one. Two years before attending hospital he was moved on the shop floor to take the place of patient 2 who had by then been shown to be sensitised to NDI. After this move he developed increasing shortness of breath and wheeze worse at night and better away from work when on holiday, but not at weekends. He had attributed his symptoms to smoking 30 cigarettes a day. He was non-atopic. He was admitted to hospital for bronchial provocation testing in April 1978.

\section{Bronchial provocation testing}

Since each of the patients tested was known to have been exposed to TDI, MDI, and NDI, sensitisation to any or all of these three isocyanates was possible. The exposure techniques with TDI and MDI as well as histamine and exercise testing have been described elsewhere (O'Brien et al, 1979b). Inhalation challenges were performed in a sealed cubicle measuring $6 \mathrm{~m}^{3}$. Atmospheric levels of TDI and MDI were measured with a model 700 UEI meter. NDI could not be measured in this way, and atmospheric levels were not recorded. Exposure to NDI in patients 1 and 2 was effected by inhalation of the vapour of $0.3 \mathrm{~g}$ of NDI crystals heated with prepolymer for a total of 60 seconds. The third patient was exposed for 60 seconds to the vapour of $500 \mathrm{mg}$ of NDI crystals heated at $110^{\circ} \mathrm{C}$. In each case bronchial reactivity to hista- mine and to exercise was also measured. Each test was conducted on a different day, and no testing was performed if the patient had suffered an asthmatic reaction on the previous day. An immediate bronchial reaction was defined as a fall in $\mathrm{FEV}_{1}$ of $15 \%$ or more within one hour of new exposure and a non-immediate reaction as a fall in $\mathrm{FEV}_{1}$ of $15 \%$ or more within 12 hours of exposure as compared with a control day painting with unreacted polyurethane varnish. A dual reaction comprised both components.

The first patient had an asthmatic reaction provoked by histamine nebulised for 30 seconds in a final concentration of $32 \mathrm{mg} / \mathrm{ml}$ but not to exercise. He developed no reactions to TDI in concentrations up to $0.0025 \mathrm{ppm}$ or to MDI in concentrations up to $0.008 \mathrm{ppm}$ but had a dual reaction provoked by NDI (fig 1 ).

Patients 2 and 3 showed no reactions to exercise or to histamine in increasing concentrations to $32 \mathrm{mg} / \mathrm{ml}$ or to TDI at concentrations of 0.001 ppm and $0.018 \mathrm{ppm}$ respectively. The third patient was also tested with MDI at a concentration of $0.02 \mathrm{ppm}$ (the threshold limit value, TVL). Both patients had non-immediate reactions provoked by exposure to NDI only (figs 2 and 3).

\section{Follow-up}

After evidence of sensitisation to NDI had been obtained by provocation testing, each patient was advised to avoid further exposure by giving up his job.

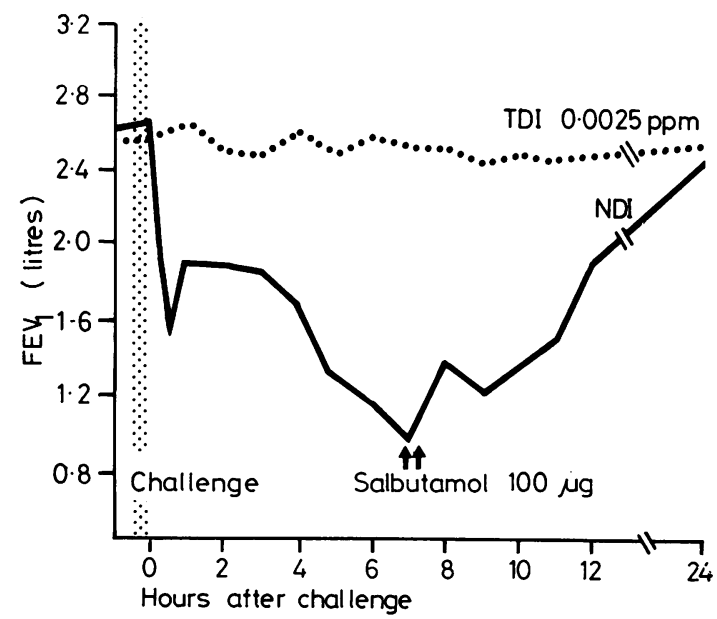

Fig 1 Patient 1. Bronchial provocation test by exposure to 1,5-naphthylene di-isocyanate (NDI) vapour for 60 s showing both immediate and nonimmediate (dual) reactions. No reaction to toluene di-isocyanate $(T D I)$. 


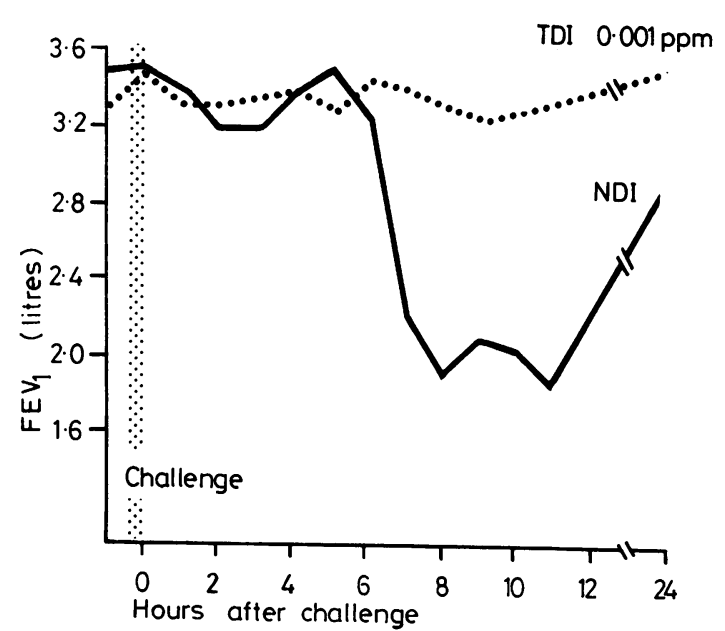

Fig 2 Patient 2. Bronchial provocation test by exposure to NDI vapour for 60 s showing an early non-immediate reaction. No reaction to TDI.

The first patient worked in an office isolated from the shop floor until October 1978 when he gave up his job. He has not knowingly been exposed to isocyanates since. His lung function showed evidence of persistent airway narrowing that is still seen in lung function tests three months after the move (table 1). In 1976 he was exposed to TDI at a level not less than $0.004 \mathrm{ppm}$ and had to be carried from the factory with a severe asthmatic attack (though when he was in hospital for testing one year previously he had developed no reactions to TDI when tested at a level not less than $0.0025 \mathrm{ppm}$ ). His symptoms are now controlled with salbutamol $200 \mu \mathrm{g}$ four times daily.
The second patient was advised to give up his? job but could not find other work. He was moved to another location on the factory floor that wasconsidered safer. His respiratory symptoms per $\Omega$ sisted, and he was treated with beclomethasonew diproprionate $100 \mu \mathrm{g}$ thrice daily. One year ago he $\overrightarrow{0}$ moved to yet another part of the factory where heis still potentially exposed to the fume of NDI $\vec{\omega}$ (table 2). He is reluctant to be followed up.

The third patient left the factory after his sensitisation had been confirmed. He is now unem- $\not$ ployed. His symptoms are improved, and he now. only requires salbutamol by inhalation occasionally (table 3).

\section{Discussion}

Evidence that NDI causes asthma from occu- $\frac{\AA}{\triangle}$ pational-type bronchial provocation testing has not been reported before. Sensitivity to NDI is much less common than that to TDI, HDI, or MDI. A $\vec{\theta}$ possible explanation for this is that it is much lessc widely used in industry and that it is less volatile than the other isocyanates so far mentioned. In these cases, however, NDI was being heated with a prepolymer mix to $135^{\circ} \mathrm{C}$, a temperature above its melting point. Another factor of possible im- $\frac{\mathbb{Q}}{\Omega}$ portance is that all the patients were heavy smokers. A cigarette tip burns at a temperature above $700^{\circ} \mathrm{C}$, and contamination of the paper with NDI powder might result in inhalation of vapour. O'Brien et al (1979a) have shown that there is no correlation between smoking and sensitisation to TDI but this is volatile at room tem- $\underset{x}{x}$ perature, and smoking would not be expected to $\dot{\circ}$ exert any special influences on exposure.

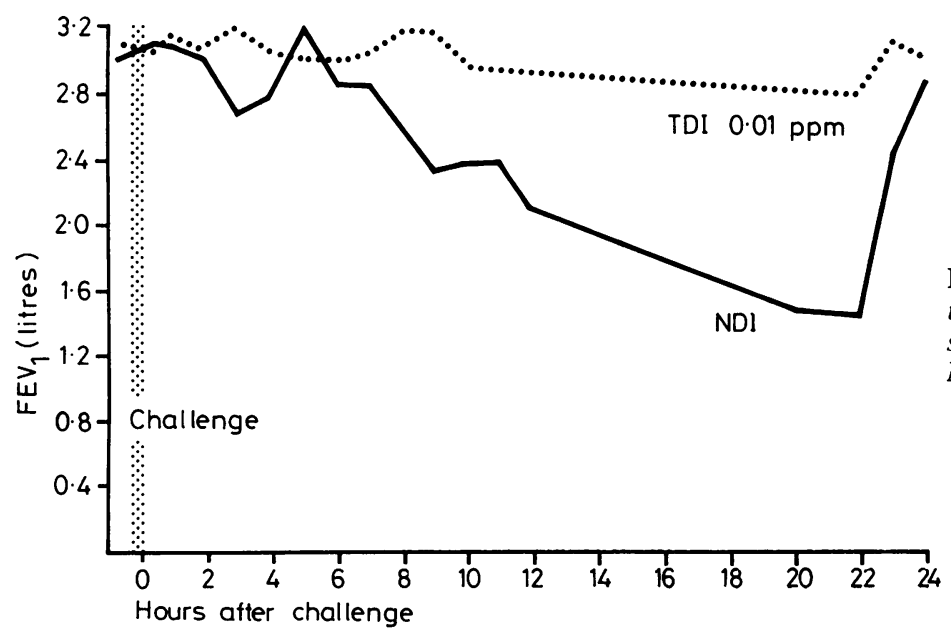

Fig 3 Patient 3. Bronchial provocation test by exposure to NDI vapour for $60 \mathrm{~s}$ showing a late non-immediate reaction. No reaction to $T D I$. 
Table 1 Serial lung function measurements in patient 1 sensitised to NDI by November 1975 showing persistent airways obstruction with continued exposure. By 10 January 1979 he had been away from work two months

\begin{tabular}{lcrrrr}
\hline & Predicted & 25.1 .76 & 10.11 .76 & 29.6 .77 & 10.1 .79 \\
\hline FEV $_{1}(\mathrm{ml})$ & $3070-4160$ & 3250 & 2570 & 2250 & 2420 \\
FVC $(\mathrm{ml})$ & $3990-5400$ & 5000 & 4880 & 4530 & 5120 \\
FEV $/$ FVC (\%) & $68-79$ & 54 & 53 & 50 & 47 \\
TLC (ml) & $5720-7750$ & 9720 & 8550 & 7980 & 9380 \\
RV (ml) & $1890-2550$ & 4070 & 3350 & 3680 & 3830 \\
After & & & & & \\
bronchodilators & & & 2850 & 2640 & 3060 \\
FEV & & & 5030 & 5060 & 5550 \\
FVC & & & 57 & 52 & 55 \\
FEV $_{1} /$ FVC & & & & & \\
\hline
\end{tabular}

Table 2 Serial lung function measurements in patient 2 known to be sensitised to NDI but reluctant to attend for follow-up

\begin{tabular}{lccc}
\hline & Predicted & 8.4 .75 & 13.9 .78 \\
\hline FEV $_{1}(\mathrm{ml})$ & $2670-3610$ & 2500 & 2450 \\
FVC $(\mathrm{ml})$ & $3280-4450$ & 3300 & 3250 \\
FEV $/$ FVC (\%) & $71-82$ & 76 & 75 \\
TLC (ml) & $4460-6040$ & 5260 & - \\
RV (ml) & $1350-1830$ & 2010 & - \\
After bronchodilators & & & \\
FEV & & 2700 & 2730 \\
FVC & & 3800 & 3450 \\
FEV $_{1} /$ FVC & & 71 & 79 \\
\hline
\end{tabular}

Table 3 Serial lung function measurements in patient 3 sensitised to NDI by A pril 1978. Unexposed since then

\begin{tabular}{lccrr}
\hline & Predicted & 14.3 .78 & 10.4 .78 & 8.1 .79 \\
\hline FEV $_{1}(\mathrm{ml})$ & $3330-4510$ & 3120 & 3520 & 3260 \\
FVC $(\mathrm{ml})$ & $4180-5660$ & 4730 & 4630 & 4660 \\
FEV $/$ FVC (\%) & $72-83$ & 66 & 76 & 70 \\
TLC (ml) & $5720-7750$ & 6150 & 6650 & 6690 \\
RV (ml) & $1740-2360$ & 1550 & 2650 & 1540 \\
After bronchodilators & & & & \\
FEV & & 3090 & & 3370 \\
FVC & & 4670 & & 4640 \\
FEV $/$ FVC & & 66 & & 73 \\
\hline
\end{tabular}

Sensitisation to isocyanate depends on several factors including the nature of exposure and the reactivity of the patient. The nature of exposure in all three was similar since they all worked in the same factory and patients 2 and 3 did identical jobs.

The reactivity of the patient judged by his atopic status, exercise tolerance, and histamine reactivity does not correlate well with proneness to sensitisation but O'Brien et al (1979a) have shown that those subjects highly sensitive to TDI reacting to levels less than $0.001 \mathrm{ppm}$ did have increased bronchial lability to histamine. None of the subjects we tested had exercise asthma, and none of them reacted to TDI at an atmospheric level less than $0.001 \mathrm{ppm}$. Only the first patient reacted to histamine at a final concentration of $32 \mathrm{mg} / \mathrm{ml}$ with a $20 \%$ fall in $\mathrm{FEV}_{1}$.

The mechanism of sensitisation to isocyanates is unclear, but both allergic and pharmacological mechanisms have been suggested. Karol et al (1978) have found IgE antibodies against the tolyl group of TDI suggesting that isocyanates are haptogenic with the reactive portion, the NCO group, binding with serum proteins, and Zeiss et al (1979) has found specific IgE and IgG antibody to human serum albumen MDI conjugates in two patients sensitised to MDI. Butcher et al (1976) and Davies et al (1977) on the other hand have suggested that TDI acts as a beta-adrenergic receptor antagonist based on its inhibitory effect on isoprenaline-induced increase in the 3,5 cyclic AMP level in lymphocytes.

A major problem in the interpretation of asthmatic reactions to the various isocyanates is knowing to which of them the patient has been exposed in the past. Many of the industrial processes used are highly secret, and the patient may not know what chemicals are being used. Furthermore, one isocyanate may be contaminated by small quantities of another, to which some individuals may react at very low atmospheric concentrations.

Though advised to give up work immediately evidence of sensitisation had been demonstrated, only one of our patients felt able to accept this advice. The reason for this was difficulty in finding alternative employment; the patient who left is still unemployed. Follow-up in the two who remained exposed shows persistent airway narrowing, and now three months after avoidance of known exposure in one of these there is still evidence of reversible airways obstruction. Prolonged measurement of peak flow rates at home and at work in sensitised patients exposed to TDI has shown a recovery pattern longer than 70 days in some cases (Burge et al, 1979).

\section{References}

Burge, P S, O'Brien, I M, and Harries, M G (1979). Peak flow rate records in the diagnosis of occupational asthma due to isocyanates. Thorax, 34, 317-323.

Butcher, B T, Salvaggio, J E, Weill, H, and Ziskind, M M (1976). Toluene di-isocyanate pulmonary disease: immunologic and inhalation challenge 
studies. Journal of Allergy and Clinical Immunology, 58, 89-100.

Davies, R J, Butcher, B T, O'Neil, C E, and Salvaggio, J E (1977). The "in vitro" effect of toluene diisocyanate on lymphocyte cyclic adenosine monophosphate production by isoproterenol, prostaglandin and histamine-a possible mode of action. Journal of Allergy and Clinical Immunology, 60, 223-229.

Fuchs, S, and Valade, P (1951). Etude clinique et expérimentale sur quelques cas d'intoxication par de desmodur $T$ (di-isocyanate de toluylène 1-2-4 et 1-2-6). Archives Maladies Professionelles, 12, 191196.

Goldblatt, M W and Goldblatt, J (1956). In Industrial Medicine and Hygiene, vol III. Edited by E R A Merewether, pp 430, 426, and 423. Butterworth, London.

Karol, M H, Ioset, H H, and Alarie, Y C (1978) Tolylspecific IgE antibodies in workers with hypersensitivity to toluene di-isocyanate. Abstract American Industrial Hygiene Conference, May 1978.

Longley, E O (1964). Methane di-isocyanates: A respiratory hazard? Archives of Environmental Health, 8, 898.
Munn, A (1965). Hazards of isocyanates. Annals of Occupational Hygiene, 8, 163-169.

O'Brien, I M, Newman Taylor, A J, Burge, P S, Harries, M G, Fawcett, I W, and Pepys, J (1979a). Toluene di-isocyanate asthma: II Inhalation challenge tests and bronchial reactivity studies. Clinical Allergy, 9, 7-16.

O'Brien, I M, Harries, M G, Burge, P S, and Pepys, J (1979b). Toluene di-isocyanate-induced asthma: I Reactions to TDI, MDI, HDI and histamine. Clinical Allergy, 9, 1-6.

Tanser, A R, Bourke, M P, and Blandford, A G (1973). Isocyanate asthma. Respiratory symptoms caused by diphenylmethane di-isocyanate. Thorax, 28, 596-600.

Zeiss, C R, Kanellakes, T, Bellone, J, Levitz, D, Pruzansky, J J, and Patterson, R (1979). IgG and $\mathrm{IgE}$ antibody to two workers with diphenylmethan di-isocyanate (MDI) induced respiratory reactions. (Abstract) American Academy of Allergy 35th Annual Meeting No 52 p 26.

Requests for reprints to: Dr M G Harries, Department of Medicine, Guys Hospital, London Bridge. 